\title{
Incidence, Prevalence, and Geographical Clustering of Motor Neuron Disease in the Netherlands
}

Adriaan D. de Jongh, MD, Ruben P.A. van Eijk, MD, PhD, MSc, Susan M. Peters, PhD, Michael A. van Es, MD, PhD, Anja M.C. Horemans, PhD, Anneke J. van der Kooi, MD, PhD, Nicol C. Voermans, MD, PhD,

Roel C.H. Vermeulen, PhD, Jan H. Veldink, MD, PhD, * and Leonard H. van den Berg, MD, PhD*

Neurology ${ }^{\circledR} 2021 ; 96:$ e1227-e1236. doi:10.1212/WNL.0000000000011467

\section{Abstract}

\section{Objective}

To assess time trends in motor neuron disease (MND) incidence, prevalence, and mortality and to investigate geographic clustering of MND cases in the Netherlands from 1998 to 2017, we analyzed data from the Netherlands Personal Records database, the Netherlands MND Center, and the Netherlands Patient Association of Neuromuscular Diseases.

\section{Methods}

In this prospective cohort study, Poisson regression was used to assess time trends in MND risk. We calculated age- and sex-standardized, observed, and expected cases for 1,694 areas. Bayesian smoothed risk mapping was used to investigate geographic MND risk.

\section{Results}

We identified 7,992 MND cases, reflecting an incidence of 2.64 (95\% confidence interval [CI] 2.62-2.67) per 100,000 person-years and a prevalence of 9.5 (95\% CI 9.1-10.0) per 100,000 persons. Highest age-standardized prevalence and mortality rates occurred at a later age in men than in women $(p<0.001)$. Unadjusted mortality rates increased by $53.2 \%$ from 2.57 per 100,000 person-years in 1998 to 3.86 per 100,000 person-years in 2017. After adjustment for age and sex, an increase in MND mortality rate of $14.1 \%$ (95\% CI 5.7\%-23.2\%, $p<0.001$ ) remained. MND relative risk ranged from 0.78 to 1.43 between geographic areas; multiple urban and rural high-risk areas were identified.

\section{Conclusions}

We found a significant national increase in MND mortality from 1998 through 2017, explained only partly by an aging Dutch population, and a geographic variability in MND risk, suggesting a role for environmental or demographic risk factors.
Correspondence Dr. van den Berg L.H.vandenBerg@ umcutrecht.nl

\footnotetext{
*These authors contributed equally to this work.
}

From the Department of Neurology (A.D.d.J., R.P.A.v.E., M.A.v.E., J.H.V., LH.v.d.B.), Brain Center Rudolf Magnus, Biostatistics \& Research Support (R.P.A.v.E.), and Julius Center for Health Sciences and Primary Care (R.C.H.V.), University Medical Center Utrecht; Institute for Risk Assessment Sciences (S.M.P., R.C.H.V.), Utrecht University, the Netherlands; National Patient Organization for Neuromuscular Diseases (A.M.C.H.), Baarn; Department of Neurology (A.J.v.d.K.), Amsterdam UMC, University of Amsterdam, Amsterdam Neuroscience; and Department of Neurology (N.C.V.), Donders Center for Neuroscience, Radboud University Medical Center, Nijmegen, the Netherlands.

Go to Neurology.org/N for full disclosures. Funding information and disclosures deemed relevant by the authors, if any, are provided at the end of the article. 


\section{Glossary}

ALS = amyotrophic lateral sclerosis; $\mathbf{C I}=$ confidence interval; DPR = Netherlands Personal Records; ENCALS = European Network for the Cure of ALS; ICD-10 = International Classification of Diseases, 10th revision; MND = motor neuron disease; $\mathbf{R R}=$ relative risk.

Motor neuron disease (MND) is a fatal neurodegenerative disease caused by both genetic and environmental factors, many of which remain to be elucidated. ${ }^{1,2}$ Worldwide MND incidence and prevalence have been shown to be increasing in the last decades. ${ }^{3}$ Aging of the world population is seen as its primary driver but does not account entirely for the increasing incidence and prevalence. ${ }^{3,4}$ This indicates that important genetic or potentially preventable environmental risk factors are currently driving the increase in MND risk. Urgent identification of these risk factors is paramount given the debilitating and care-intensive nature of MND and its future effect on health care services. ${ }^{2,5}$

Although assessing whether MND risk is increasing may aid planning of health services, it does not directly identify underlying risk factors. Geographic studies, on the other hand, can stimulate etiologic research by identifying specific disease clusters. Examples are identification of patient clusters in Guam $^{6}$ and the Kii Peninsula ${ }^{7}$ that were subsequently linked to neurotoxic plant consumption and the $C 9$ orf 72 repeat expansion. Studies of time trends or clusters have, however, often been limited by methodologic issues such as incomplete case ascertainment or geographic risk assessment in a limited area. ${ }^{8}$

We therefore use multiple, independent, national data sources in the Netherlands, including a nationwide population-based study operational since 2006, to determine the change in MND incidence, prevalence, mortality rates and survival time in the Netherlands over the last 2 decades and to investigate geographic clustering of MND cases.

\section{Methods}

\section{Data Sources}

Three independent sources of prospectively collected data were used to estimate incidence, prevalence, and mortality of adult-onset MND (that is, amyotrophic lateral sclerosis [ALS], primary lateral sclerosis, and progressive muscular atrophy) in the Netherlands. The first source was the Netherlands Personal Records (DPR) database covering the period from 1998 to 2017. All Dutch residents are registered in the DPR database, and Dutch law requires that all deaths in the Netherlands be registered by a physician according to the ICD-10. MND (ICD-10 codes G12.21-G12.24) is registered as the cause of death even if it was an underlying cause (e.g., in the case of death due to pneumonia). We also selected Alzheimer cases (ICD-10 code G30) to compare the effect of age on Alzheimer and MND mortality rates. As a second source, we used data from the population-based Netherlands MND
Center registry, described in more detail elsewhere. ${ }^{9}$ In brief, patients diagnosed with MND, according to the revised $\mathrm{El}$ Escorial criteria, ${ }^{10}$ have been prospectively registered centrally by the Netherlands MND Center since 2006. Patients were identified via annual screening of large hospital registries and specialized MND rehabilitation clinic registries and by contacting neurologists individually. ${ }^{9}$ Survival times after date of diagnosis (date of death or date last known to be alive) were obtained for patients in the Netherlands MND registry by checking the online municipal register at 3-month intervals. Third, patients were identified within the register of a national patient advocacy organization, the Netherlands Patients Association for Neuromuscular Diseases. ${ }^{11}$

\section{Statistical Analysis}

Comprehensive MND health surveillance estimates were calculated as follows. Age- and sex-adjusted incidence and mortality rates were calculated by dividing the number of observed cases by the person-years of observation. Cases were identified in the DPR database from 1998 through 2017 and in the Netherlands MND registry from 2006 through 2017. MND prevalence was the number of MND patients alive on December 31, 2017, expressed as a proportion of the total Dutch population. The number of unobserved cases in the MND registry was estimated via 2 methods. First, 2-source capture-recapture methodology was applied to each 5-year age and sex stratum, using data from the MND registry and the Netherlands Patients Association for Neuromuscular Diseases. Capture-recapture methodology aims to correct for underascertainment in health surveillance studies ${ }^{12}$ and has been successfully applied in other neuromuscular epidemiologic studies. ${ }^{13}$ The Chapman ${ }^{12}$ formulas were used to estimate the total number of patients with prevalent MND and the proportion identified by the MND registry. As a sensitivity analysis, we also estimated incidence and prevalence on the basis of the MND deaths per year recorded in the DPR database. Individual survival times were sampled from a Weibull distribution ${ }^{14}$ and subtracted from the date of death to calculate date of diagnosis. Simulations were repeated 50,000 times to obtain empirical $95 \%$ confidence intervals (CIs) for incidence and prevalence estimates.

Next, we assessed whether MND mortality rates changed between 1998 and 2017. We used a Poisson generalized linear model and data from the DPR database to estimate MND mortality rate per year. We incorporated age (quadratic), sex, their interaction, and years since 1998 as covariates with the natural logarithm of population size as an offset. To test both whether the effect of age differs across sexes and whether rates have increased since 1998, we tested each term using a 
likelihood ratio test. As a sensitivity analysis, we evaluated how loss of competing risks and longevity of a subpopulation susceptible to MND influence MND mortality rates as described elsewhere. ${ }^{15}$ We evaluated whether patient characteristics of the Netherlands MND registry changed between early periods (2006-2009) and late periods (2014-2017). Cox regression was used to assess whether survival recorded by the Netherlands MND registry changed from 2006 through 2017. The hazard ratio for time in years since 2006 was adjusted for the patient's individual risk profile according to the European Network for the Cure of ALS (ENCALS) survival prediction model. ${ }^{16}$ The ENCALS risk profile is a relative measure and indicates whether a patient's survival time is shorter or longer relative to other patients. Five prognostic subgroups were defined on the basis of the quintiles of the individual risk profiles. ${ }^{17}$ Missing values in baseline characteristics, necessary to determine the ENCALS risk profile, were accounted for by creating 100 imputed datasets as described earlier. ${ }^{17}$ Estimates were pooled across imputations with the Rubin rules. ${ }^{18}$

Finally, we evaluated the geographic distribution of MND cases in the Netherlands. To map MND risk and to identify both high- and low-risk areas, data from the DPR database were used. As per January 1, 2018, the Netherlands comprises 13,305 geographic areas (i.e., neighborhoods). The DPR database contains detailed individual residential history data, dating from approximately 1990. The address where a case had resided the longest since 1990 was used to calculate the number of observed cases per geographic area. Nationwide mortality rates per 5-year age and sex group were applied to the mean population per time period to calculate the number of expected MND cases per geographic area. To obtain sufficient sample size to conduct spatial smoothing of MND risk, areas with an expected incidence of $<3$ cases (i.e., $\leq 6,000$ residents from 1998 through 2017) were merged iteratively with adjacent areas with the lowest expected incidence, until all areas had at least an expected incidence of 3. Next, crude standardized mortality ratios were calculated by dividing the observed by the expected number of cases. Standardized mortality ratios were subsequently smoothed to estimate MND relative risk (RR) per area by using a bayesian autoregression model with local random effects as described elsewhere. ${ }^{18}$ As an example, a RR of 1.3 means that the observed MND rate in that area is estimated to be $30 \%$ higher than expected (i.e., the national rate of $\mathrm{MND}$ ). ${ }^{8}$ For each area, we determined the posterior probability that the local risk of MND would be either lower or higher than the national risk according to 10,000 draws from the posterior distribution (i.e., the posterior probability that $\mathrm{RR}<1.0$ or $\mathrm{RR}>1.0$, respectively). Bayesian analyses control for multiplicity by using a conservative prior that shrinks all estimates toward the null hypothesis (i.e., an RR of 1.0). Therefore, it is not necessary to adjust the posterior probability for multiplicity. In addition, the prior ensures that the MND RR can be estimated even in rural areas when data are sparse. As an exploratory analysis, we assessed the weighted association between $R R$ and the average age, percentage of men, and population density per area. Population density was analyzed as number of residents per square kilometer. The following definitions from Statistics Netherlands were used: $<500$ (very low), 500 to 1,000 (low), 1,000 to 1,500 (average), 1,500 to 2,500 (high), and >2,500 (very high).

\section{Standard Protocol Approvals, Registrations, and Patient Consents}

This study is reported according to the Standards of Reporting of Neurological Disorders guideline. ${ }^{19}$ The medical ethics committee and institutional review board of the University Medical Center Utrecht approved this study.

\section{Data Availability}

All protocols, analyses, and anonymized data will be shared on request from any qualified investigator. Access to data from the DPR database can be requested from Statistics Netherlands (CBS) via cbs.nl/en-gb/our-services/customised-services-microdata/microdata-conducting-your-own-research/ microdata-catalogue.

\section{Results}

\section{MND Incidence, Prevalence, and Mortality}

From 1998 through 2017, there were, on average, 16.4 million residents and a total of 3.2 million deaths recorded in the Netherlands, of which 7,992 (0.25\%) were MND related. The total number of patients with incident MND in this time period was estimated to be 8,676 (95\% CI 8,585-8,767), resulting in an average annual incidence of 2.64 (95\% CI $2.62-2.67)$ per 100,000 person-years. Since the start of the MND registry in 2006, the number of incident patients was $5,764,4,152(72.0 \%)$ of whom were identified by the MND registry. Table 1 presents their patient characteristics; patients identified via the MND registry were, on average, younger (67.7 years vs 69.7 years) and more likely to be male (58.4\% vs $54.8 \%$ ) compared to patients in the DPR database.

On December 31, 2017, we identified 1,215 prevalent patients in the MND registry (source 1) and the Netherlands Patient Association for Neuromuscular Diseases (source 2). A total of 953 patients were unique to source 1,83 were unique to source 2, and 179 patients were identified by both sources. The total number of prevalent patients with MND was estimated at 1,654 , resulting in a prevalence of 9.6 (95\% CI 9.5-9.8) per 100,000 persons (supplementary table 1 , doi. org/10.5061/dryad.4xgxd257d). The simulation-based sensitivity analysis based on data from the DPR database resulted in a similar prevalence estimate $(n=1,639$ patients, 9.5 per 100,000 persons).

Overall MND incidence and mortality rates were highest in the 70- to 74-year and 75- to 79-year age groups, respectively (figure 1). Incidence and prevalence data are available in Dryad (figure 1, doi.org/10.5061/dryad.4xgxd257d). There was a differential effect of age for men and women 
Table 1 Baseline Characteristics of the Netherlands MND Registry and Netherlands Personal Records Database

\begin{tabular}{|c|c|c|c|c|}
\hline Patient Characteristic & $\begin{array}{l}\text { MND Registry } \\
2006-2009(n=1,190)\end{array}$ & $\begin{array}{l}\text { MND Registry } \\
2014-2017(n=1,573)\end{array}$ & $\begin{array}{l}\text { MND Registry } \\
2006-2017(n=4,152)\end{array}$ & $\begin{array}{l}\text { Personal Records } \\
\text { Database 1998-2017 } \\
(\mathrm{n}=7,992)\end{array}$ \\
\hline Age at diagnosis, y & $63.7(63.1-64.4)$ & $66.0(65.5-66.5)$ & $65.0(64.7-65.4)$ & - \\
\hline Age at death, $y$ & $66.6(65.9-67.2)$ & $68.7(68.2-69.3)$ & $67.7(67.4-68.1)$ & $69.7(69.4-70.0)$ \\
\hline Male sex, \% (n) & $59.0(702)$ & $58.2(915)$ & $58.4(2,424)$ & $54.8 \%(4,380)$ \\
\hline \multicolumn{5}{|l|}{ MND subtype } \\
\hline ALS, \% (n) & 79.4 (944) & $74.9(1,179)$ & $80.2(3,329)$ & - \\
\hline PMA, \% (n) & $13.7(163)$ & $17.3(271)$ & $13.3(554)$ & - \\
\hline PLS, \% (n) & $7.0(83)$ & $7.8(123)$ & $6.5(269)$ & - \\
\hline Spinal onset, \% (n) & $70.2(835)$ & $73.2(1,152)$ & $71.5(2,967)$ & - \\
\hline Diagnostic delay, mo ${ }^{a}$ & $11.4(9.9-12.9)$ & $11.0(9.7-12.4)$ & $11.0(10.7-11.3)$ & - \\
\hline ALSFRS-R total score at diagnosis & $39.0(38.7-39.4)$ & $38.7(38.5-39.0)$ & $39.0(38.8-39.1)$ & - \\
\hline$\Delta \mathrm{FRS}^{\mathrm{a}}$ & $0.56(0.54-0.58)$ & $0.51(0.50-0.53)$ & $0.54(0.53-0.55)$ & - \\
\hline $\begin{array}{l}\text { Vital capacity, } \% \text { of predicted } \\
\text { value at diagnosis }\end{array}$ & $86.9(85.3-88.5)$ & $87.6(86.4-88.8)$ & $87.7(86.9-88.6)$ & - \\
\hline C9orf72 carrier, \% (n) & $7.2(86)$ & $6.7(106)$ & $7.0(289)$ & - \\
\hline Frontotemporal dementia, \% (n) & $5.2(62)$ & $11.3(1,395)$ & $7.5(310)$ & - \\
\hline Family history of MND, \% (n) & $6.7(80)$ & $8.4(1,395)$ & $7.1(294)$ & - \\
\hline \multicolumn{5}{|l|}{ ENCALS risk profile, $\%(n)^{b}$} \\
\hline Very short survival & $12.7(120)$ & $18.1(213)$ & $15.5(517)$ & - \\
\hline Short survival & $22.4(212)$ & $22.2(261)$ & $22.3(744)$ & - \\
\hline Intermediate survival & $16.8(159)$ & $19.0(224)$ & $18.4(611)$ & - \\
\hline Long survival & $20.6(195)$ & $20.3(239)$ & $20.5(682)$ & - \\
\hline Very long survival & $27.5(260)$ & $20.5(242)$ & $23.3(775)$ & - \\
\hline
\end{tabular}

Abbreviations: ALS = amyotrophic lateral sclerosis; ALSFRS-R = revised ALS Functional Rating Scale; $\triangle F R S=(48-$ ALSFRS-R total score)/diagnostic delay in months; ENCALS = European Network for the Cure of ALS; MND = motor neuron disease; PLS = primary lateral sclerosis; PMA = progressive muscular atrophy. Data are mean (95\% confidence interval) or percent (number). The ENCALS risk profile is a relative measure and indicates whether a patient's survival time is shorter or longer relative to other patients. The Netherlands Personal Records database contains data on all Dutch residents, including date and cause of death. MND cases in the Netherlands Personal Records database were defined as deaths with MND (ICD code G12.2) as a contributing cause of death. Due to privacy regulations and because clinical data are not collected, limited data were available for these patients.

${ }^{a}$ Medians are presented for diagnostic delay and $\triangle$ FRS because of skewed distributions.

${ }^{\mathrm{b}}$ Patient's individual risk profile according to the ENCALS survival prediction model. ${ }^{16}$

(i.e., different shape of the age-standardized rates graphs in figure 1) on incidence ( $p<0.01$ for interaction term), prevalence, and mortality (both $p<0.001$ ). For example, highest MND prevalence and mortality rates occurred at later ages for men compared to women ( $80-84$ years vs $75-79$ years, respectively). In contrast, highest Alzheimer mortality rates occurred in the oldest age group ( $>95$ years) for both men and women (figure 1D).

\section{Time Trends}

In 2017, $0.31 \%$ of all recorded deaths in the Netherlands were MND related, resulting in a lifetime risk of 1 in 323. The absolute number of MND deaths increased from 299 in 1998 to 466 in 2017 with an average annual increase of $2.7 \%$ (95\%
CI $2.4 \%-3.1 \%$ ) (figure 2A). Unadjusted estimated mortality rates increased by $53.2 \%$ (95\% CI $42.0 \%-65.4 \%, p<0.001$ ) from 2.57 in 1998 to 3.86 per 100,000 person-years in 2017 (figure $2 \mathrm{~B}$ ).

Overall, we found no evidence that the increase in MND mortality rates differed among age groups ( $p=0.57$ for interaction term). The observed increase did, however, seem to be driven largely by younger age groups; mortality rates increased by $60.3 \%$ ( $95 \%$ CI $40.8 \%-82.6 \%$ ) in people $<70$ years of age and by $15.6 \%$ (95\% CI 4.1\%-28.4\%) in age groups $>70$ years. After adjustment for age and sex, MND mortality rates increased by $14.1 \%(95 \%$ CI $5.7 \%-23.2 \%, p<0.001)$ in this time period; this increase was similar for men and women $(p=$ 

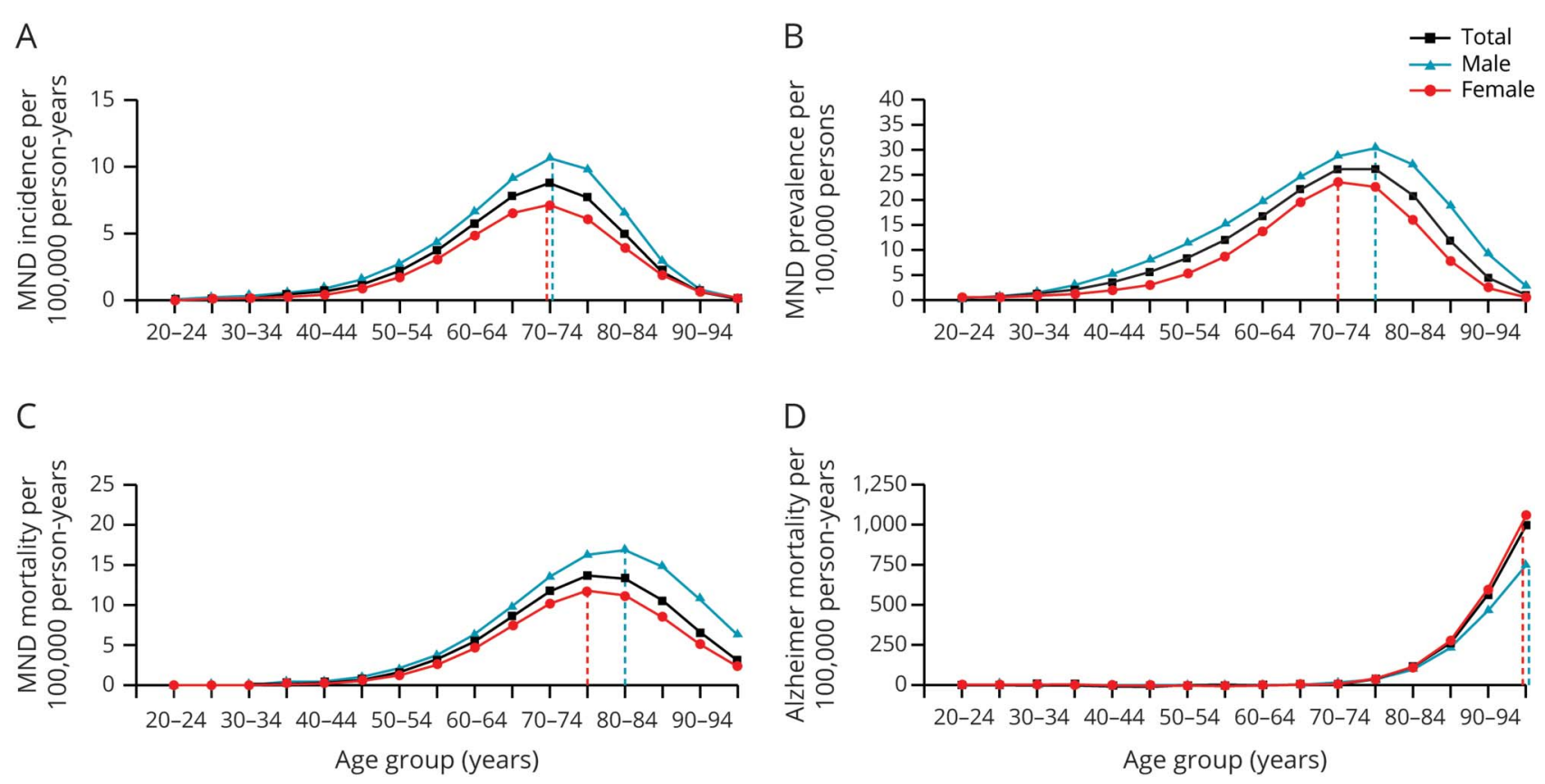

This panel plot shows motor neuron disease (MND) (A) incidence, (B) prevalence, and (C) mortality and (D) Alzheimer mortality in the Netherlands from 1998 through 2017 determined via Poisson regression. Dashed lines indicate the age group with maximum rates. There was a differential effect of age for men and women on incidence $(p<0.01$ for interaction term), prevalence, and mortality (both $p<0.001)$. For example, highest MND prevalence and mortality rates occurred at later ages for men than for women. In contrast, highest Alzheimer mortality rates occurred in the oldest age group ( $>95$ years) for both men and women. This suggests that MND risk is not merely a result of aging. Age- and sex-stratified MND incidence was determined on the basis of data from the Netherlands MND registry. MND prevalence was determined by capture-recapture methodology using data from the Netherlands MND registry and Netherlands Patient Association for Neuromuscular Diseases. MND mortality and Alzheimer mortality were determined from mortality records in the Netherlands Personal Records database.

0.62 for interaction term) (figure 2C). Consequently, the average male:female ratio among MND cases did not increase significantly over time $(p=0.09)$ and was, on average, 1.19 (95\% CI 1.14-1.25) (figure 2D). Similarly, the mean age at death due to MND in the DPR database was, on average, 69.7 years and did not significantly change during the study period (change in age was 0.62 years, $95 \% \mathrm{CI}-0.23$ to $1.47, p=0.15$ ).

In contrast to the observed increase in MND mortality rates, age- and sex-adjusted mortality rates from competing (i.e., non-MND) causes of death decreased by $1.98 \%$ (95\% CI $1.96 \%-2.00 \%)$ per year. This annual decrease was larger for men than for women ( $p<0.001$ for interaction term): $2.48 \%$ (95\% CI 2.41\%-2.54\%) and 1.51\% (95\% CI 1.48\%-1.54\%) for men and women, respectively. As a sensitivity analysis, we used the Gompertz model ${ }^{15}$ to evaluate whether longevity of a subpopulation susceptible to MND, as a result of loss of competing risks, may be driving the increase in MND mortality rates. We estimated that the susceptible subpopulation decreased by -253 men per 100,000 (95\% CI -529 to $23, p=$ 0.05 ) and by -210 women per 100,000 (95\% CI -356 to -56 , $p=0.006)$.

Figure $3 \mathrm{~A}$ shows the annual distribution of the 5 prognostic subgroups defined by the ENCALS personalized prediction model of patients enrolled in the Netherlands MND registry since 2006. According to the ENCALS prediction model, the average risk profile at time of diagnosis has worsened since $2006(p<0.001)$, meaning that in recent years more patients have been diagnosed with a relatively poor risk profile. This finding is in line with table 1 , which shows that, even though diagnostic delay had not significantly changed since 2006 $(-0.76$ months, $95 \% \mathrm{CI}-4.4$ to $2.9, p=0.31)$, the average age of patients with MND had increased and more patients had been diagnosed with concomitant frontotemporal dementia since 2006. This suggests that the Netherlands MND registry has become more population based by improving recruitment strategies to ascertain patients with incident disease instead of a mixture of patients with incident and prevalent disease (i.e., long-surviving) in earlier register years. Figure 3B shows the adjusted annual probability of survival in the Netherlands. The adjusted risk of death during follow-up decreased by $16.2 \%$ during the time period of 2006 to 2017 (hazard ratio per 5 years 0.93 , 95\% CI 0.88-0.98, $p=0.006$ ). This resulted in an adjusted median survival time that increased from 19.6 months (95\% CI 18.7-20.9) to 22.4 months (95\% CI 21.1-23.7) for patients diagnosed in 2006 and 2017, respectively.

\section{Mapping of MND Risk}

Finally, the probability that local MND risk is higher than expected (i.e., the national MND risk) per geographic area is 


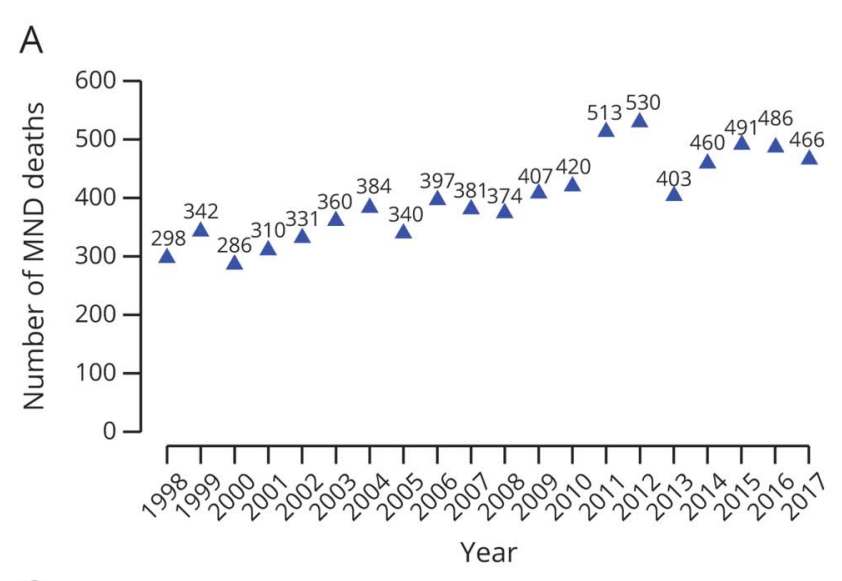

B

C
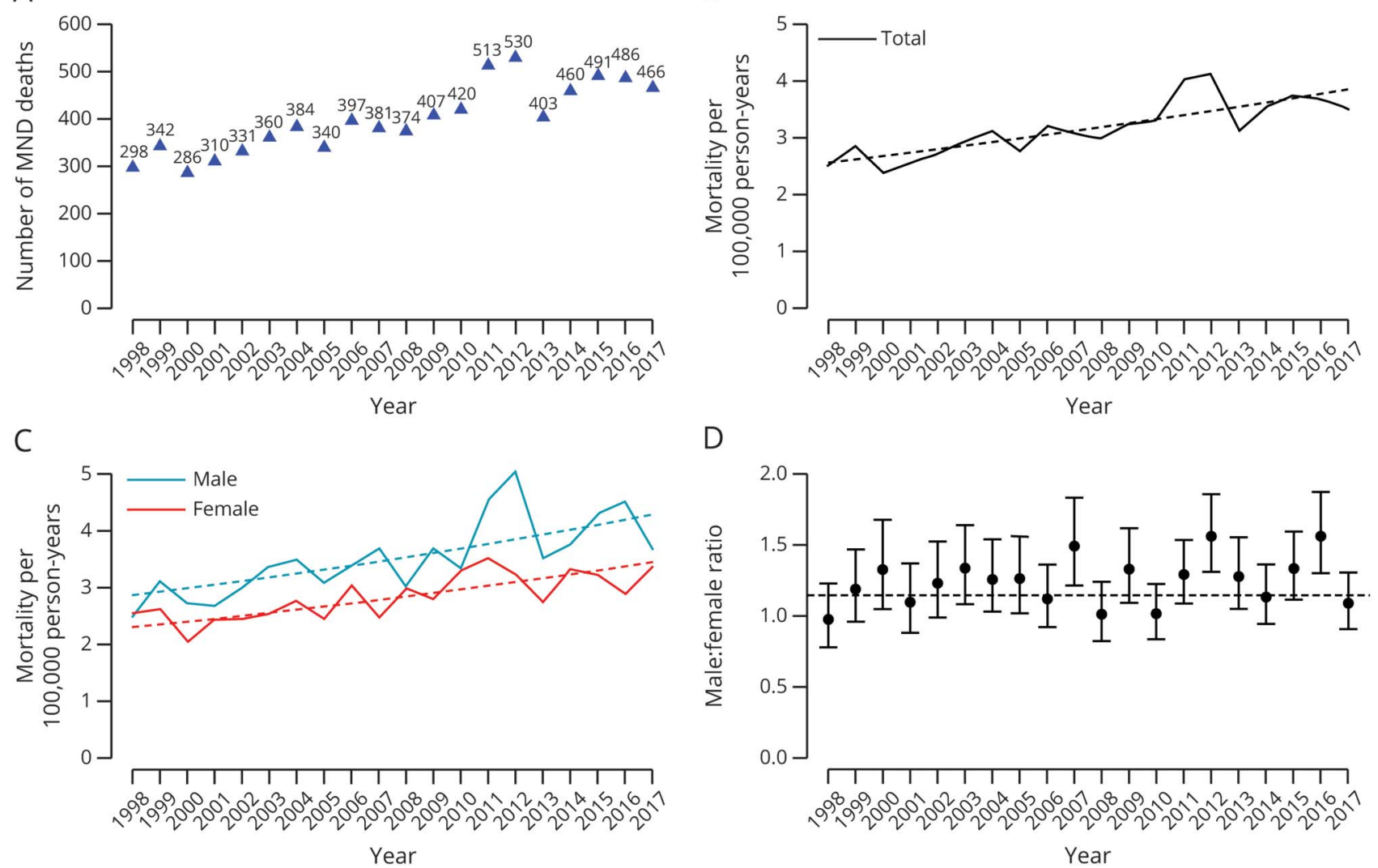

D

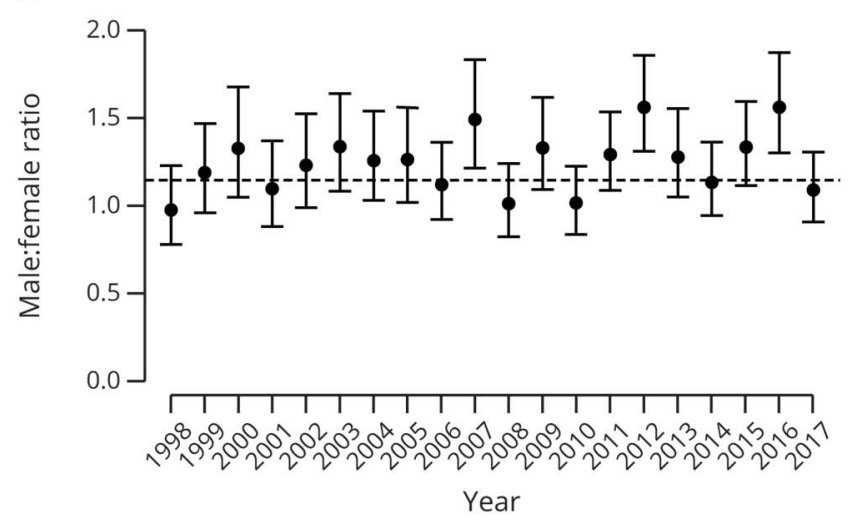

(A) Number of motor neuron disease (MND) deaths observed in the Netherlands between 1998 and 2017. Absolute number of MND deaths increased from 299 in 1998 to 466 in 2017 with an average annual increase of 2.6\%. (B) Adjusted for population size, mortality rates increased by $53.2 \%$ or by $14.1 \%$ After additional age and sex adjustment (both $p<0.001$ ) in the time period of 1998 to 2017 , dashed lines indicate regression lines. (C) MND mortality rates are provided separately for men (blue) and women (red). Annual increase in MND mortality rates was not different for men and women ( $p=0.62$ for interaction term). (D) Similar to panel C, we provide the annual male:female ratio, revealing a stable sex ratio of 1.19 (dashed line) over time ( $p=0.09$ for time trend).

shown in figure 4 . The DPR database contained 1 patient with a missing address $(0.01 \%)$. After merging of areas to obtain sufficient sample sizes, there were 1,694 areas with a median population size of 9,507 residents and 4.0 observed MND cases per area. We found geographic variation in MND risk with RRs ranging from 0.78 to 1.43 , with the highest risk near Ten Boer in the province of Groningen and the lowest risk near Wijk bij Duurstede in the province of Utrecht. The table in figure 4 presents areas that have a probability of at least 0.90 that local MND risk is either higher or lower than national MND risk (i.e., $R R>1.0$ or $R R<1.0$ ). We identified 10 areas, both urban and rural, with a $>0.90$ probability of either high or low MND risk scattered across the Netherlands. As an exploratory analysis, we assessed whether population density, mean age, and proportion of men per area were related to MND risk. Median population density was 2,591 residents per $1 \mathrm{~km}^{2}$ (range, 82-14,452) and was not significantly related to MND risk: RR changed by $-0.015 \%$ (95\% CI -0.006 to $0.003)$ for every doubling in population density $(p=0.49)$. Similarly, mean age and proportion of men were also unrelated. The changes in RR for a 10-year increase in mean age and an absolute increase of $10 \%$ in the proportion of men were 0.003 ( $95 \%$ CI -0.024 to $0.0295, p=0.85$ ) and -0.79 ( $95 \%$ CI -5.94 to $4.35, p=0.76$ ), respectively.

\section{Discussion}

In this study, we used multiple independent data sources to provide comprehensive health surveillance estimates of MND in the Netherlands from 1998 to 2017, resulting in an average estimated incidence of 2.64 per 100,000 person-years, a prevalence of 9.5 per 100,000 persons, and a lifetime MND risk of 1 in 323. Mean diagnostic delay did not significantly change while median survival time improved by 3 months from 2006 through 2017, possibly as a result of improved multidisciplinary care. This observed increase in median survival time could imply that the increase in MND incidence may be larger than the observed increase in MND mortality rates since 1998. After age and sex adjustment, MND mortality rates increased by $14.1 \%$ over the last 2 decades in both men and women. The $53.2 \%$ increase in unadjusted MND 

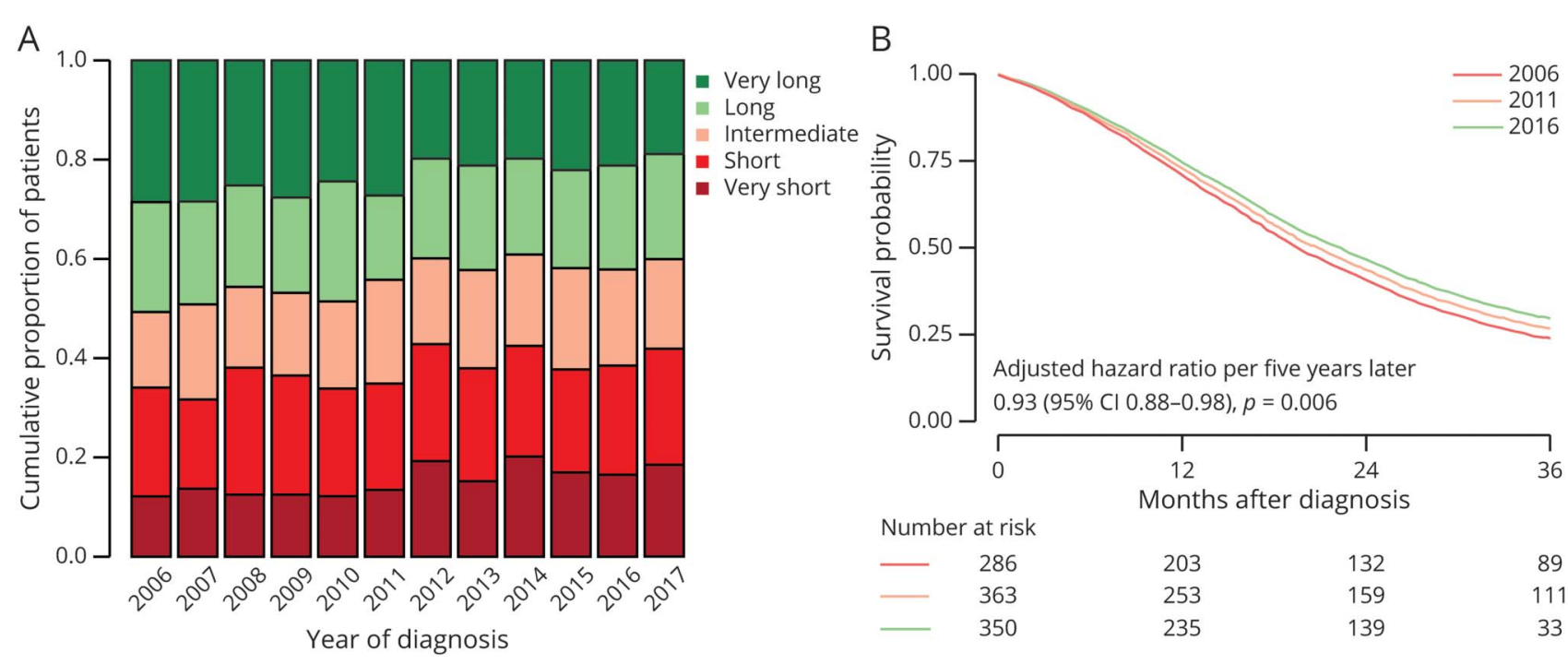

(A) Annual distribution of the 5 prognostic subgroups defined by the European Network for the Cure of ALS (ENCALS) personalized prediction model. Ideally, each prognostic subgroup should have a prevalence of $\approx 20 \% / y$. As can be seen, in 2006 , the Netherlands motor neuron disease (MND) registry enrolled relatively more very long- and long-surviving patients, indicating that the registry recruited mainly prevalent cases. Fortunately, as recruitment strategies improved to register also short- and very short-surviving subgroups, the Netherlands MND registry has become more population based. (B) Effect of year of diagnosis on survival time was modeled with a Cox proportional hazards model adjusted for the ENCALS risk prediction. Risk of death during follow-up decreased by $16.2 \%$ between 2006 and 2017 (hazard ratio per 5 years $0.93,95 \%$ confidence interval [Cl] 0.88-0.98, $p=0.006$ ). Adjusted median survival increased from 19.6 months $(95 \% \mathrm{Cl} 18.7-20.9)$ in 2006 to 22.4 months $(95 \% \mathrm{Cl} 21.1-23.7)$ in 2017.

mortality rates could have significant consequences for planning of future health care services in that it may indicate a doubling of MND prevalence by the year 2050. Our results suggest that either genetic or potentially preventable environmental risk factors are driving MND risk, and urgent

Figure 4 Probability of Elevated MND Risk in the Netherlands by Geographic Area

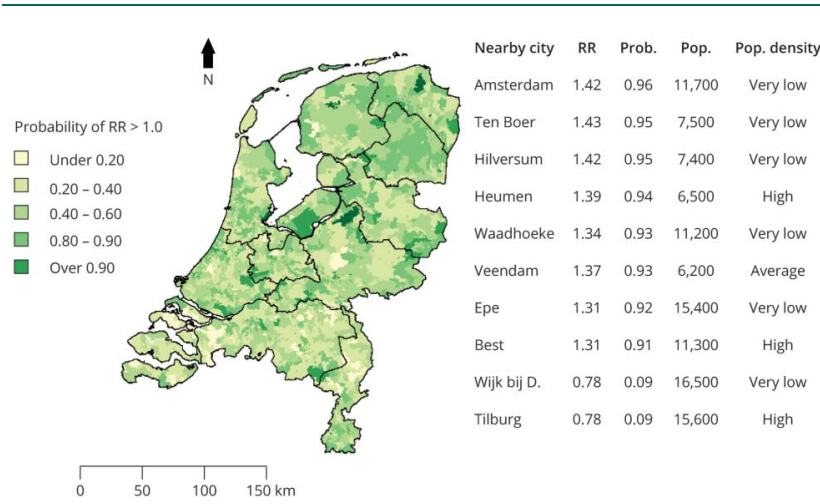

Motor neuron disease (MND) relative risk for 1,694 areas was calculated and subsequently smoothed based on data from the Dutch Personal Records database from 1998 to 2017. This map shows the probability (Prob) that MND relative risk (RR) per area is greater than expected according to the national rate of MND (i.e., the probability of $R R>1.0$ based on 10,000 draws from the posterior distribution). Population (Pop) density was estimated as number of residents per $1 \mathrm{~km}^{2}$; the following definitions from Statistics Netherlands were used: $<500$ (very low), 500 to 1,000 (low), 1,000 to 1,500 (average), 1,500 to 2,500 (high), and >2,500 (very high). Wijk bij D. = Wijk bij Duurstede. identification is needed, which may be aided by detailed geographic studies of MND risk.

We found a different effect of age when comparing MND and Alzheimer risk. The decline of MND risk in the oldest age groups contrasts with the risk of Alzheimer and suggests that there is a time period of maximal susceptibility and that MND is not only a result of aging. Short survival in cases of MND compared to cases of Alzheimer may also play a role. MND may be exclusive to a small susceptible subpopulation, the majority of whom are deceased by 70 to 80 years of age as a result of either MND or other unrelated causes. There is evidence that loss of competing risks and longevity of this susceptible subpopulation could also be driving the increase in MND mortality rates. ${ }^{15}$ Indeed, we found that the risk of death due to causes other than MND decreased during the study period. Our findings of a reduction of the size of a susceptible subpopulation and larger increase of MND mortality rates among younger age groups, however, contrast with this hypothesis. Nevertheless, we cannot rule out that longevity of a susceptible subpopulation might had affected the increase of MND mortality rates.

Aging of the general population is an important driver of the increasing incidence of neurodegenerative diseases. ${ }^{20} \mathrm{An}$ earlier study found no statistically significant change in MND incidence in Minnesota in the United States in the period of 1925 to $1998 .{ }^{21}$ In contrast, several studies have indicated that MND incidence has increased in the last 2 decades. ${ }^{3,4,22}$ For example, in an epidemiologic study in Northern Italy, MND 
incidence increased by $14 \%$ from 1995 to 2014, mostly in women. ${ }^{4}$ A possible explanation for the larger increase in MND incidence in more recent years may be that those born during the baby boom after World War II reached ages with highest incidence in the period of 2005 to 2017. Most studies were based on registry data only while using capture-recapture methodology to correct for underascertainment, which can underestimate or overestimate the total number of cases when data sources are not independent. ${ }^{23}$ In our study, we have therefore performed both capture-recapture and simulationbased sensitivity analyses with 3 independent data sources, including unselected data from a national compulsory health database. In absolute terms, the number of cases per year increased from 298 in 1998 to 466 in 2017. If this increase continues, the lifetime risk of MND would increase to 1 in 205 by 2050 . This observed increase is not driven solely by aging of the general population, which could explain only $\approx 75 \%$ of the increase. Increased awareness and timelier referral of patients suspected of having MND since the start of the Netherlands MND Center in 2003 may play a role, although several environmental risk factors that have been linked to MND could be involved such as exposure to organic dust, agricultural pesticides, air pollution, and other occupational hazards. $^{24-27}$

To help develop hypotheses as to which risk factors are currently driving MND risk, we mapped geographic MND risk from 1998 through 2017 to identify high-risk areas. The use of national data is particularly advantageous because assessing geographic risk in a limited area is an approach known to exaggerate the likelihood of identifying high-risk areas. ${ }^{8}$ There was considerable spatial variation in MND risk, which indicates that associating spatial risk with characteristics of that particular area may be worthwhile (i.e., identify factors that explain spatial variation in risk). For example, by quantifying risk factors such as lifestyle, physical activity levels, and environmental exposures in well-defined geographic areas, ${ }^{27-29}$ we may be able to efficiently identify risk factors. We have illustrated its potential use by associating MND risk with population density, which may act as a proxy for other risk factors. ${ }^{30}$ Although we found no direct correlation of population density with MND risk, its simplicity could stimulate etiologic research in MND. For example, air pollution could be more severe in cities; by combining spatial risk estimates with exposure levels, on both an individual and a geographic level, one may increase power to find potential associations. A similar approach may hold true for exposure to agricultural pesticides, which are more common in rural areas. An illustrative example of the latter is the increased risk of Parkinson disease in the Netherlands associated with living in the vicinity of agricultural fields where pesticides are used. ${ }^{31}$ Furthermore, genetic risk factors may also cause geographic variability in MND risk. ${ }^{7}$ Previously, studies found that rare genetic variants appear to be important drivers of MND risk ${ }^{32}$ and that genetic variation can be localized geographically, meaning that there is relatively little migration in the Netherlands. ${ }^{33}$ As a result, local MND incidence may increase via a genetic founder effect when new genetic variations occur. We hypothesize that both environmental risk factors, unique to each area, and local genetic admixture may thus explain geographic variation in MND risk. Quantification of a broad spectrum of risk factors, both on an individual level as per geographic area, remains paramount.

Due to privacy regulations, our study was limited in that we could not confirm a clinical diagnosis in the DPR database for individual cases. Therefore, we cannot rule out some misclassification in the DPR database. Nevertheless, we considered the DPR database to be of a high standard for several reasons. Because registration is mandatory, the DPR database includes all Dutch residents. Furthermore, it is likely that patients with MND will visit a neurologist at least once because the Dutch public healthcare system ensures that there are no financial or physical hurdles to receiving health care. As a result, it is probable that if a patient receives an MND diagnosis, this will also be communicated to that individual's general practitioner or nursing home physician. Dutch law requires that a physician (usually the general practitioner or nursing home physician) list all possible contributing causes of death on the death certificate. In addition, we found that both age at death and male:female ratio were stable, suggesting that case ascertainment has not changed during the study period. Moreover, the incidence and prevalence estimates that we found are in line with estimates found in other North European countries with compulsory national health databases. In Denmark, Norway, and Sweden, incidence and prevalence estimates ranged from 2.47 to 3.54 per 100,000 person-years and 8.0 to 8.7 per 100,000 persons, respectively. ${ }^{34-40}$ Last, we found similar prevalence estimates using capture-recapture methodology and a simulation-based approach using data from independent sources, thus further confirming the accurate case ascertainment of the data sources used.

Using the national DPR database enabled us to assess that $72.0 \%$ of all Dutch patients with MND were identified by the Netherlands MND registry. This coverage rate is comparable to or higher than other large population-based registries. ${ }^{41-43}$ The higher mean age of patients and higher proportion of female patients in the DPR database suggest that older female patients may be underrepresented in the Dutch populationbased MND registry. This unintended selection of younger male patients with, on average, longer survival was also observed when trial participants were compared to the eligible MND population. ${ }^{17}$ It is important to recognize this unintended selection of patients because it can lead to biased effect sizes in population-based studies when investigating etiologic risk factors or genes. ${ }^{29,44}$ To resolve unintended selection in population-based studies, future studies that investigate reasons for nonparticipation in observational studies are needed to identify these as-yet unknown patient factors.

We found a national $53.2 \%$ increase in MND mortality rates from 1998 through 2017 in both men and women. This large 
increase in the last 2 decades underlines the impact that the care of patients with MND will have on health services in the future. There was geographic variation in MND risk, which could be related to local genetic admixture or complex environmental risk factors. Associating spatial risk with possible MND risk factors could stimulate etiologic research in MND.

\section{Study Funding}

This study was funded by the Netherlands ALS Foundation.

\section{Disclosure}

The authors report no disclosures relevant to the manuscript. Go to Neurology.org/N for full disclosures.

\section{Publication History}

Received by Neurology July 29, 2020. Accepted in final form October 26, 2020.

Appendix Authors

\begin{tabular}{lll}
\hline Name & Location & Contribution \\
\hline Adriaan D. de & University Medical Center & Design and \\
Jongh, MD & Utrecht, the Netherlands & $\begin{array}{l}\text { conceptualization of } \\
\text { study, acquired and } \\
\text { analyzed data, performed } \\
\text { statistical analysis; drafted } \\
\text { manuscript }\end{array}$ \\
& &
\end{tabular}

\begin{tabular}{|c|c|c|}
\hline $\begin{array}{l}\text { Ruben P.A. } \\
\text { van Eijk, MD, } \\
\text { PhD }\end{array}$ & $\begin{array}{l}\text { University Medical Center } \\
\text { Utrecht, the Netherlands }\end{array}$ & $\begin{array}{l}\text { Analyzed data, performed } \\
\text { statistical analysis, and } \\
\text { drafted manuscript }\end{array}$ \\
\hline $\begin{array}{l}\text { Susan M. } \\
\text { Peters, PhD }\end{array}$ & $\begin{array}{l}\text { Utrecht University, the } \\
\text { Netherlands }\end{array}$ & $\begin{array}{l}\text { Design and } \\
\text { conceptualization of } \\
\text { study, drafted manuscript }\end{array}$ \\
\hline $\begin{array}{l}\text { Michael A. } \\
\text { van Es, MD, } \\
\text { PhD }\end{array}$ & $\begin{array}{l}\text { University Medical Center } \\
\text { Utrecht, the Netherlands }\end{array}$ & $\begin{array}{l}\text { Acquired data and revised } \\
\text { the manuscript for } \\
\text { intellectual content }\end{array}$ \\
\hline $\begin{array}{l}\text { Anja M.C. } \\
\text { Horemans, } \\
\text { PhD }\end{array}$ & $\begin{array}{l}\text { National Patient } \\
\text { Organization for } \\
\text { Neuromuscular Diseases, } \\
\text { Baarn, the Netherlands }\end{array}$ & $\begin{array}{l}\text { Acquired data and revised } \\
\text { the manuscript for } \\
\text { intellectual content }\end{array}$ \\
\hline $\begin{array}{l}\text { Anneke J. } \\
\text { van der Kooi, } \\
\text { MD, PhD }\end{array}$ & $\begin{array}{l}\text { University Medical Center, } \\
\text { Amsterdam, the } \\
\text { Netherlands }\end{array}$ & $\begin{array}{l}\text { Acquired data and revised } \\
\text { the manuscript for } \\
\text { intellectual content }\end{array}$ \\
\hline $\begin{array}{l}\text { Nicol C. } \\
\text { Voermans, } \\
\text { MD, PhD }\end{array}$ & $\begin{array}{l}\text { Radboud University } \\
\text { Medical Center, Nijmegen, } \\
\text { the Netherlands }\end{array}$ & $\begin{array}{l}\text { Acquired data and revised } \\
\text { the manuscript for } \\
\text { intellectual content }\end{array}$ \\
\hline $\begin{array}{l}\text { Roel C.H. } \\
\text { Vermeulen, } \\
\text { PhD }\end{array}$ & $\begin{array}{l}\text { Utrecht University, the } \\
\text { Netherlands }\end{array}$ & $\begin{array}{l}\text { Design and } \\
\text { conceptualization of } \\
\text { study, revised manuscript } \\
\text { for intellectual content. }\end{array}$ \\
\hline $\begin{array}{l}\text { Jan H. } \\
\text { Veldink, MD, } \\
\text { PhD }\end{array}$ & $\begin{array}{l}\text { University Medical Center } \\
\text { Utrecht, the Netherlands }\end{array}$ & $\begin{array}{l}\text { Acquired data and revised } \\
\text { the manuscript for } \\
\text { intellectual content }\end{array}$ \\
\hline $\begin{array}{l}\text { Leonard H. } \\
\text { van den } \\
\text { Berg, MD, } \\
\text { PhD }\end{array}$ & $\begin{array}{l}\text { University Medical Center } \\
\text { Utrecht, the Netherlands }\end{array}$ & $\begin{array}{l}\text { Design and } \\
\text { conceptualization } \\
\text { of study, acquired data, } \\
\text { and revised the } \\
\text { manuscript for } \\
\text { intellectual content }\end{array}$ \\
\hline
\end{tabular}

\section{References}

1. Al-Chalabi A, Fang F, Hanby MF, et al. An estimate of amyotrophic lateral sclerosis heritability using twin data. J Neurol Neurosurg Psychiatry 2010;81:1324-1326.

2. van Es MA, Hardiman O, Chio A, et al. Amyotrophic lateral sclerosis. Lancet 2017; 390:2084-2098.

3. GBD 2016 Motor Neuron Disease Collaborators. Global, regional, and national burden of motor neuron diseases 1990-2016: a systematic analysis for the Global Burden of Disease Study 2016. Lancet Neurol 2018;17:1083-1097.

4. Chio A, Mora G, Moglia C, et al. Secular trends of amyotrophic lateral sclerosis: the Piemonte and Valle d'Aosta register. JAMA Neurol 2017;74:1097-1104.

5. Moore A, Young CA, Hughes DA. Health utilities and costs for motor neurone disease. Value Health 2019;22:1257-1265.

6. Spencer PS, Nunn PB, Hugon J, et al. Guam amyotrophic lateral sclerosis-parkinsonismdementia linked to a plant excitant neurotoxin. Science 1987;237:517-522.

7. Ishiura H, Takahashi $\mathrm{Y}$, Mitsui J, et al. C9ORF72 repeat expansion in amyotrophic lateral sclerosis in the Kii Peninsula of Japan. Arch Neurol 2012;69:1154-1158.

8. Olsen SF, Martuzzi M, Elliott P. Cluster analysis and disease mapping: why, when, and how? A step by step guide. BMJ 1996;313:863-866.

9. Huisman MH, de Jong SW, van Doormaal PT, et al. Population based epidemiology of amyotrophic lateral sclerosis using capture-recapture methodology. J Neurol Neurosurg Psychiatry 2011;82:1165-1170.

10. Brooks BR, Miller RG, Swash M, Munsat TL; World Federation of Neurology Research Group on Motor Neuron Diseases. El Escorial revisited: revised criteria for the diagnosis of amyotrophic lateral sclerosis. Amyotroph Lateral Scler Other Motor Neuron Disord 2000;1:293-299.

11. Boon $\mathrm{W}$, Broekgaarden $\mathrm{R}$. The role of patient advocacy organisations in neuromuscular disease R\&D: the case of the Dutch Neuromuscular Disease Association VSN. Neuromuscul Disord 2010;20:148-151.

12. Chapman DG. Some Properties of the Hypergeometric Distribution with Applications to Zoological Sample Censuses. Berkeley: University of California Press; 1951.

13. Deenen JC, Arnts H, van der Maarel SM, et al. Population-based incidence and prevalence of facioscapulohumeral dystrophy. Neurology 2014;83:1056-1059.

14. van Eijk RPA, Nikolakopoulos S, Roes KCB, et al. Critical design considerations for time-to-event endpoints in amyotrophic lateral sclerosis clinical trials. J Neurol Neurosurg Psychiatry 2019;90:1331-1337.

15. Neilson S, Robinson I, Hunter M. Longitudinal gompertzian analysis of ALS mortality in England and Wales, 1963-1989: estimates of susceptibility in the general population. Mech Ageing Dev 1992;64:201-216.

16. Westeneng HJ, Debray TPA, Visser AE, et al. Prognosis for patients with amyotrophic lateral sclerosis: development and validation of a personalised prediction model. Lancet Neurol 2018;17:423-433.

17. van Eijk RPA, Westeneng HJ, Nikolakopoulos S, et al. Refining eligibility criteria for amyotrophic lateral sclerosis clinical trials. Neurology 2019;92:e451-60.

18. Rooney J, Heverin M, Vajda A, et al. An exploratory spatial analysis of ALS incidence in Ireland over 17.5 years (1995-July 2013). PLoS One 2014;9:e96556.

19. Bennett DA, Brayne C, Feigin VL, et al. Development of the Standards of Reporting of Neurological Disorders (STROND) checklist: a guideline for the reporting of incidence and prevalence studies in neuroepidemiology. Neurology 2015;85: $821-828$.

20. GBD 2016 Neurology Collaborators. Global, regional, and national burden of neurological disorders, 1990-2016: a systematic analysis for the Global Burden of Disease Study 2016. Lancet Neurol 2019;18:459-480.

21. Sorenson EJ, Stalker AP, Kurland LT, Windebank AJ. Amyotrophic lateral sclerosis in Olmsted County, Minnesota, 1925 to 1998. Neurology 2002;59:280-282.

22. Fang F, Valdimarsdottir U, Bellocco R, et al. Amyotrophic lateral sclerosis in Sweden, 1991-2005. Arch Neurol 2009;66:515-519.

23. Tilling K. Capture-recapture methods: useful or misleading? Int J Epidemiol 2001;30: $12-14$.

24. Seelen M, Toro Campos RA, Veldink JH, et al. Long-term air pollution exposure and amyotrophic lateral sclerosis in Netherlands: a population-based case-control study. Environ Health Perspect 2017;125:097023.

25. Visser AE, D'Ovidio F, Peters S, et al. Multicentre, population-based, case-control study of particulates, combustion products and amyotrophic lateral sclerosis risk. J Neurol Neurosurg Psychiatry 2019;90:854-860.

26. Peters S, Visser AE, D'Ovidio F, et al. Associations of electric shock and extremely low-frequency magnetic field exposure with the risk of amyotrophic lateral sclerosis. Am J Epidemiol 2019;188:796-805.

27. Huisman MH, Seelen M, van Doormaal PT, et al. Effect of presymptomatic body mass index and consumption of fat and alcohol on amyotrophic lateral sclerosis. JAMA Neurol 2015;72:1155-1162.

28. Visser AE, Rooney JPK, D'Ovidio F, et al. Multicentre, cross-cultural, populationbased, case-control study of physical activity as risk factor for amyotrophic lateral sclerosis. J Neurol Neurosurg Psychiatry 2018;89:797-803.

29. de Jong SW, Huisman MH, Sutedja NA, et al. Smoking, alcohol consumption, and the risk of amyotrophic lateral sclerosis: a population-based study. Am J Epidemiol 2012; 176:233-239.

30. Burke DS, Brundage JF, Herbold JR, et al. Human immunodeficiency virus infections among civilian applicants for United States military service, October 1985 to March 1986: demographic factors associated with seropositivity. N Engl J Med 1987;317: 131-136.

31. Brouwer M, Huss A, van der Mark M, et al. Environmental exposure to pesticides and the risk of Parkinson's disease in the Netherlands. Environ Int 2017;107:100-110. 
32. van Rheenen W, Shatunov A, Dekker AM, et al. Genome-wide association analyses identify new risk variants and the genetic architecture of amyotrophic lateral sclerosis. Nat Genet 2016;48:1043-1048.

33. Genome of the Netherlands Consortium. Whole-genome sequence variation, population structure and demographic history of the Dutch population. Nat Genet 2014; 46:818-825.

34. Vieira VM, Hansen J, Gredal O, Weisskopf MG. Spatial analyses of ALS incidence in Denmark over three decades. Amyotroph Lateral Scler Frontotemporal Degener 2018;19:275-284.

35. Kioumourtzoglou MA, Seals RM, Himmerslev L, Gredal O, Hansen J, Weisskopf MG. Comparison of diagnoses of amyotrophic lateral sclerosis by use of death certificates and hospital discharge data in the Danish population. Amyotroph Lateral Scler Frontotemporal Degener 2015;16:224-229.

36. Seals RM, Hansen J, Gredal O, Weisskopf MG. Physical trauma and amyotrophic lateral sclerosis: a population-based study using Danish national registries. Am J Epidemiol 2016;183:294-301.

37. Nakken O, Lindstrom JC, Tysnes OB, Holmoy T. Assessing amyotrophic lateral sclerosis prevalence in Norway from 2009 to 2015 from compulsory nationwide health registers. Amyotroph Lateral Scler Frontotemporal Degener 2018;19:303-310.
38. Longinetti E, Mariosa $\mathrm{D}$, Larsson $\mathrm{H}$, et al. Neurodegenerative and psychiatric diseases among families with amyotrophic lateral sclerosis. Neurology 2017;89:578-585.

39. Longinetti E, Regodon Wallin A, Samuelsson K, et al. The Swedish motor neuron disease quality registry. Amyotroph Lateral Scler Frontotemporal Degener 2018;19: $528-537$.

40. Sun J, Zhan Y, Mariosa D, et al. Antibiotics use and risk of amyotrophic lateral sclerosis in Sweden. Eur J Neurol 2019;26:1355-1361.

41. Zhou S, Qian S, Li X, Zheng L, Chang W, Wang L. Using the capture-recapture method to estimate the incidence of amyotrophic lateral sclerosis in Beijing, China. Neuroepidemiology 2018;50:29-34.

42. Golby R, Poirier B, Fabros M, Cragg JJ, Yousefi M, Cashman N. Five-year incidence of amyotrophic lateral sclerosis in British Columbia (2010-2015). Can J Neurol Sci 2016;43:791-795.

43. Nelson LM, Topol B, Kaye W, et al. Estimation of the prevalence of amyotrophic lateral sclerosis in the United States using national administrative healthcare data from 2002 to 2004 and capture-recapture methodology. Neuroepidemiology 2018;51: 149-157.

44. Hill G, Connelly J, Hebert R, Lindsay J, Millar W. Neyman's bias re-visited. J Clin Epidemiol 2003;56:293-296. 


\section{Neurology}

\section{Incidence, Prevalence, and Geographical Clustering of Motor Neuron Disease in the Netherlands}

Adriaan D. de Jongh, Ruben P.A. van Eijk, Susan M. Peters, et al.

Neurology 2021;96;e1227-e1236 Published Online before print January 20, 2021

DOI 10.1212/WNL.0000000000011467

This information is current as of January 20, 2021

\section{Updated Information \&} Services

References

Subspecialty Collections

Permissions \& Licensing

Reprints including high resolution figures, can be found at: http://n.neurology.org/content/96/8/e1227.full

This article cites 43 articles, 12 of which you can access for free at: http://n.neurology.org/content/96/8/e1227.full\#ref-list-1

This article, along with others on similar topics, appears in the following collection(s):

Amyotrophic lateral sclerosis

http://n.neurology.org/cgi/collection/amyotrophic_lateral_sclerosis_ Anterior nerve cell disease

http://n.neurology.org/cgi/collection/anterior_nerve_cell_disease

Incidence studies

http://n.neurology.org/cgi/collection/incidence_studies

Prevalence studies

http://n.neurology.org/cgi/collection/prevalence_studies

Information about reproducing this article in parts (figures,tables) or in its entirety can be found online at:

http://www.neurology.org/about/about_the_journal\#permissions

Information about ordering reprints can be found online:

http://n.neurology.org/subscribers/advertise

Neurology ${ }^{\circledR}$ is the official journal of the American Academy of Neurology. Published continuously since 1951, it is now a weekly with 48 issues per year. Copyright Copyright (C) 2021 The Author(s). Published by Wolters Kluwer Health, Inc. on behalf of the American Academy of Neurology.. All rights reserved. Print ISSN: 0028-3878. Online ISSN: 1526-632X.

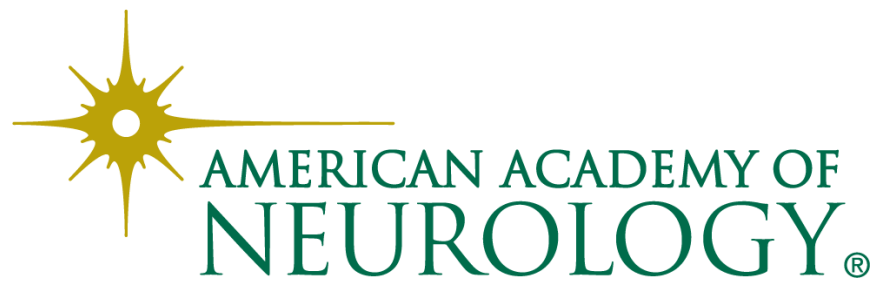

